RESEARCH ARTICLE

\title{
FORMULATION AND EVALUATION OF RAPIDLY DIS INTEGRATING FILM OF AMLODIPINE B ES YLATE
}

\author{
Shelke PV*, Dumbare AS, Gadhave MV, Jadhav S L, Sonawane AA, Gaikwad DD
}

Department of Pharmaceutics, Vishal Institute of Pharmaceutical Education \& Research, Ale, Pune, India, 412411

Corresponding Author's Email: - pravinshelke04@gmail.com

Received 08 Jan 2012; Revised 28 Jan 2012; Accepted 31 Jan 2012, Available online 15 March 2012

\begin{abstract}
:
Fast-dissolving drug-delivery systems were first developed in the late 1970s as an alternative to tablets, capsules, and syrups. Fast dissolving oral films (FDOFs) are the most advanced form of oral solid dosage form due to more flexibility and comfort. It improve the efficacy of APIs by dissolving within minute in oral cavity after the contact with less saliva as compared to fast dissolving tablets, without chewing and no need of water for administration. The FDOFs place as an alternative in the market due to the consumer's preference for a fast dissolving product over conventional tablets / capsules. The oral thin-film technology is still in the beginning stages and has bright future ahead because it fulfils all the need of patients. Eventually, film formulations having drug/s will be commercially launched using the oral film technology. In the present study fast dissolving film of Amlodipine Besylate was prepared using sodium alginate as film forming polymer. To decrease the disintegration time of formulations sodium starch gly colate was used as disintegrating agent. A full $3^{2}$ factorial design was applied using concentration of polymer and disintegrant as independent variable and disintegration time and \% cumulative drug release as dependent variable. Response surface curves were plotted. Batch F6 was found to be the optimized batch as its disintegration was completed within the minimum time as compared to all other batches. The formulation (F6) was also showing sufficient drug release after $6 \mathrm{~min}$. All the nine formulation was showing approximately $70-85 \%$ drug release after 6 min.
\end{abstract}

Keywords: Amlodipine Besy late, fast dissolving film, solvent casting, response surface plot, sodium algin ate.

\section{INTRODUCTION:}

The earliest developed fast dissolving technology existed in the tablet form and the rapid disintegrating properties resulted from special process or formulation modifications. Fast dissolving films are gaining popularity as an alternative to fast dissolving tablets as they eliminates patient's fear of chocking and overcome patient impediments. Fast dissolving films generally consists of plasticized hydrocolloids or blends which can be laminated by using techniques such as hot-melt extrusion and solvent casting. Additionally they also provide easy delivery of drug under emetic condition. Mouth dissolving films, are the new drug delivery system for delivery of drugs through oral cavity and was developed on the basis of technology of the transdermal patch. The delivery system consists of a very thin oral strip, which when placed on the patient's tongue or any oral mucosal tissue gets instantly wet by saliva and rapidly hydrates and adheres onto the site of application. Film then rapidly disintegrates and dissolves to release the medication for absorption through oromucosal route or with formula modifications, will maintain the quick-dissolving aspects allow for gastrointestinal absorption to be achieved when swallowed. In contrast to other existing, rapid dissolving dosage forms, which consist of liophylisates, the rapid films can be produced with a manufacturing process that is competitive with the manufacturing costs of conventional tablets. ${ }^{1}$ Angina pectoris, commonly known as angina, is chest pain due to ischemia of the heart muscle; generally due to obstruction or spasm of the coronary arteries (the heart's blood vessels). The model drug selected was amlodipine besylate. Amlodipine besylate is chemically described as 3-Ethyl-5-methyl ( \pm )-2-[(2-aminoethoxy) methyl] -4-(2-chlorophenyl)-1, 4-dihydro -6-methyl-3, 5pyridinedicarboxylate, mono benzenesulphonate monohydrate.

Amlodipine is a dihydropyridine calcium antagonist (calcium ion antagonist or slow-channel blocker) that inhibits the transmembrane influx of calcium ions into vascular smooth muscle and cardiac muscle. Experimental data suggest that amlodipine binds to both dihydropyridine and non dihydropyridine binding sites. The contractile processes of cardiac muscle and vascular smooth muscle are dependent upon the movement of extra cellular calcium ions into these cells through specific ion channels. Amlodipine inhibits calcium ion influx across cell membranes selectively, with a greater effect on vascular smooth muscle cells than on cardiac muscle cells.

Generally, the following points are considered for patient compliance in case of anti-angina patients, a rapid onset of action is necessary for immediate pain relief, patient has difficulty to swallow tablet or any another dosage form during pain, geriatrics has difficulty to swallow the dosage form. By considering the above points, patient convenience and compliance oriented research has resulted in bringing out safer and newer drug delivery systems one of such approach is fast dissolving drug delivery system. 
Conventional dosage forms for the anti-angina therapy includes tablets and injections. Injections provide effective rapid relief but, they are very painful and very expensive.

Sodium starch glycolate is widely used in oral pharmaceuticals as a disintegrant in capsule and tablet formulations. It is commonly used in tablets prepared by either direct-compression or wet granulation processes. The usual concentration employed in a formulation is between $2 \%$ and $8 \%$, with the optimum concentration about $4 \%$, although in many cases $2 \%$ is sufficient. Disintegration occurs by rapid uptake of water followed by rapid and enormous swelling. ${ }^{5}$ Glycerin is used in a wide variety of pharmaceutical formulations including oral, ophthalmic, topical, and parenteral preparations. It is also frequently used as a plasticizer in film coatings and preparation of soft gelatin capsules. ${ }^{6}$

\section{MATERIALS AND METHODS :-}

Amlodipine Besylate hydrochloride was obtained as a gift sample from Hilab Chemicals ltd., Goregaon, Mumbai(India). Sodiu m alginate, Sodium Starch Glycolate and glycerine were purchased from Hilab Chemicals ltd., Goregaon, Mumbai (India). All other chemicals and reagent were of analytical grade.

\section{COMPATIB ILITY S TUDIES :-}

\section{Fourier Transform Infrared S pectr oscopy (FT-IR):}

FT-IR spectroscopy was carried out for the following: (a) pure drug amlodipine besylate (b) amlodipine besylate with Sodium alginate (c) amlodipine besylate with SSG using Perkin Elmer FTIR model 163 by taking $\mathrm{KBr}$ disc.

\section{Formulation of films:-}

For formu lating the film sodium alg inate was dissolved in distilled water. Amlodipine Besylate and sodium starch glycolate was added to the polymer solution. When the entire solid material was dissolved in the water, required amount of plasticizer (glycerol) was added to the solution. The solution was then casted on the plastic films and dried in oven at 60 0C. Dried films were removed and stored in desiccator till further use. ${ }^{7}$

Table 1: Formulation of fast dissol ving film

\begin{tabular}{|l|l|l|l|l|l|l|l|l|l|}
\hline Ingredient & F1 & F2 & F3 & F4 & F5 & F6 & F7 & F8 & F9 \\
\hline Sodiu m alg inate (\%) & 1.25 & 1.25 & 1.25 & 1.5 & 1.5 & 1.5 & 1.75 & 1.75 & 1.75 \\
\hline Amlodipine besylate (mg) & 10 & 10 & 10 & 10 & 10 & 10 & 10 & 10 & 10 \\
\hline Aspartame & 3.9 & 3.9 & 3.9 & 3.9 & 3.9 & 3.9 & 3.9 & 3.9 & 3.9 \\
\hline SSG (\%) & 1.5 & 2 & 2.5 & 1.5 & 2 & 2.5 & 1.5 & 2 & 2.5 \\
\hline Glycerine (\%) & 20 & 20 & 20 & 20 & 20 & 20 & 20 & 20 & 20 \\
\hline Distilled water (ml) & 20 & 20 & 20 & 20 & 20 & 20 & 20 & 20 & 20 \\
\hline
\end{tabular}

\section{EVALUATION OF FILMS:}

\section{Thickness:}

All the batches were evaluated for thickness by using calibrated Vernier caliper. Three readings from all the batches were taken and mean thickness was evaluated. ${ }^{8}$

\section{Fol ding endurance :}

The folding endurance was measured manually for the prepared films. A strip of film was cut and repeatedly folded at the same place till it broke. The number of times the film could be folded at the same place without breaking gave the value of folding endurance.

\section{Drug content:}

Drug content of all nine batches was determined by UVSpectrophotometric method. For this $1 \times 1 \mathrm{~cm} 2$ strip from the each film was cut and dissolved in $10 \mathrm{ml}$ of simulated salivary fluid $(\mathrm{pH}$ 6.2). The solution was filtered and absorbance was recorded at $239 \mathrm{~nm}$. Drug content was calculated by using standard curve of drug. 8

\section{Unifor mity of drug content:}

For determining the uniformity of drug content in the film at least three strips $(1 \mathrm{x} 1 \mathrm{~cm} 2)$ were cut from different section of the film and drug content was calculated for all three strips using the same procedure as above. The drug content of all three strips was compared. Same procedure was repeated for all the nine batches. ${ }^{8}$

\section{In vitro disintegration time:}

In vitro disintegration time is determined visually in a glass dish of $25 \mathrm{ml}$ distilled water with swirling every 10 sec. The disintegration time is the time when the film starts to break or disintegrates. ${ }^{1}$

\section{In-vi tro dissolution studies:}

Dissolution study was carried out in USP basket type apparatus using the stimu lated salivary fluid $(\mathrm{pH}$ 6.2) as a dissolution medium at 50 rotations per minute. $5 \mathrm{ml}$ aliquots were withdrawn at different time intervals and same amount of fresh dissolution medium was added. The aliquots were assayed for drug content at $230.5 \mathrm{~nm}$ wavelength using UV-spectrophotometer. The cumulative percentage drug release was calculated. ${ }^{\mathbf{1 0 , 1 1 , 1 2}}$

\section{RESULT AND DISCUSSION:-}

Fast dissolving films were prepared using sodium alg inate as film forming polymer and sodium starch glycolate as disintegrating agent. The films were evaluated for various properties such as thickness, drug content etc. The result showed that all the films have a smooth surface and good folding endurance. Drug content of all the films was between 4.6 to $5.01 \mathrm{mg}$. The results are shown in table 2 . The results of weight and drug content uniformity test showed that the film was uniform and drug was also uniformly distributed in the films. Films were having thickness adequate for handling and use. The 
disintegration time of the films was evaluated using simulated salivary fluid ( $\mathrm{pH}$ 6.2). Two times readings for each batch were recorded i.e. time at which disintegration started and time when the film completely disintegrates.
The result indicates that disintegration of films initialized in about $30 \mathrm{sec}$ and completes in 142-197 sec. Batch F3 and F6 disintegrates most rapidly. The results of in-vitro dis solution of all batches are shown in figure. 1

Table 2: Evaluation of amlodipine besylate films

\begin{tabular}{|l|l|l|l|l|l|}
\hline Batch & Thickness(mm) & Weight(mg) & Drug content & \multicolumn{2}{|c|}{ Disintegration time } \\
\cline { 5 - 6 } & & & & Start & Complete \\
\hline F1 & 0.221 & 0.05 & 4.678 & 32 & 197 \\
\hline F2 & 0.135 & 0.03 & 4.923 & 28 & 178 \\
\hline F3 & 0.204 & 0.04 & 4.812 & 25 & 142 \\
\hline F4 & 0.201 & 0.03 & 4.907 & 35 & 202 \\
\hline F5 & 0.201 & 0.04 & 5.012 & 38 & 167 \\
\hline F6 & 0.125 & 0.03 & 4.827 & 30 & 142 \\
\hline F7 & 0.158 & 0.04 & 4.926 & 39 & 200 \\
\hline F8 & 0.202 & 0.03 & 4.995 & 35 & 175 \\
\hline F9 & 0.167 & 0.04 & 4.988 & 32 & 153 \\
\hline
\end{tabular}

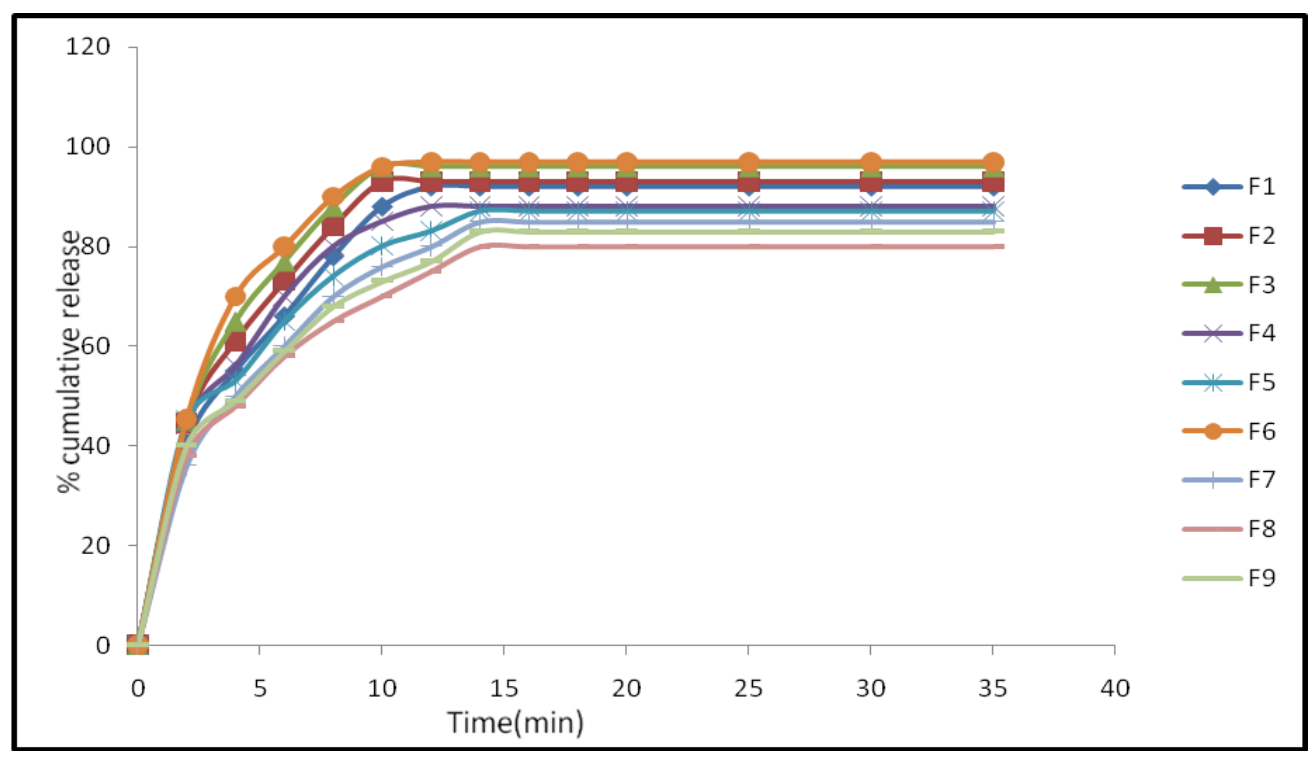

Figure 1: In-vitro dissolution studies of fast dissol ving films

Table 3: Regression equation for each response variable determined by multiple regression analysis

\begin{tabular}{|l|l|l|l|l|}
\hline $\begin{array}{l}\text { S. } \\
\text { No. }\end{array}$ & $\begin{array}{l}\text { Independent } \\
\text { variables }\end{array}$ & $\begin{array}{l}\text { Regression } \\
\text { coefficient }\end{array}$ & $\begin{array}{l}\text { Y1 ( \% cumulative drug } \\
\text { released after 6 minutes) }\end{array}$ & $\begin{array}{c}\text { Y2 } \\
\text { (disintegration time) }\end{array}$ \\
\hline 1 & $\mathrm{~b} 0$ & - & 80.1356 & 32.6667 \\
\hline 2 & $\mathrm{~b} 1$ & $\mathrm{X} 1$ & -6.5667 & 3.5000 \\
\hline 3 & $\mathrm{~b} 2$ & $\mathrm{X} 2$ & 5.4683 & -3.1667 \\
\hline 4 & $\mathrm{~b} 12$ & $\mathrm{X} 1 \mathrm{x} 2$ & - & - \\
\hline 5 & $\mathrm{~b} 1 \mathrm{~b} 2$ & $\mathrm{X} 1 \mathrm{x} 1$ & - & - \\
\hline 6 & $\mathrm{~b} 2 \mathrm{~b} 2$ & $\mathrm{X} 2 \mathrm{x} 2$ & - & - \\
\hline
\end{tabular}

A full $3^{2}$ factorial design was applied to study the effect of independent variables (conc. of sodium alginate and conc. of sodium starch glycolate) on the dependent variable (disintegration time and \% cumulative drug release after 6 $\min )$. Various coefficients have been shown in table 3.

Response surface plots were plotted which are shown in figure $2 \&$ figure 3 . Response surface plots showed that the
$\%$ cumulative drug release after 6 minutes inversely proportional to the concentration of sodium alg inate and directly proportional to concentration of sodium starch glycolate. The disintegration time is inversely proportional to concentration of SSG and directly proportional to concentration of sodium alginate. 


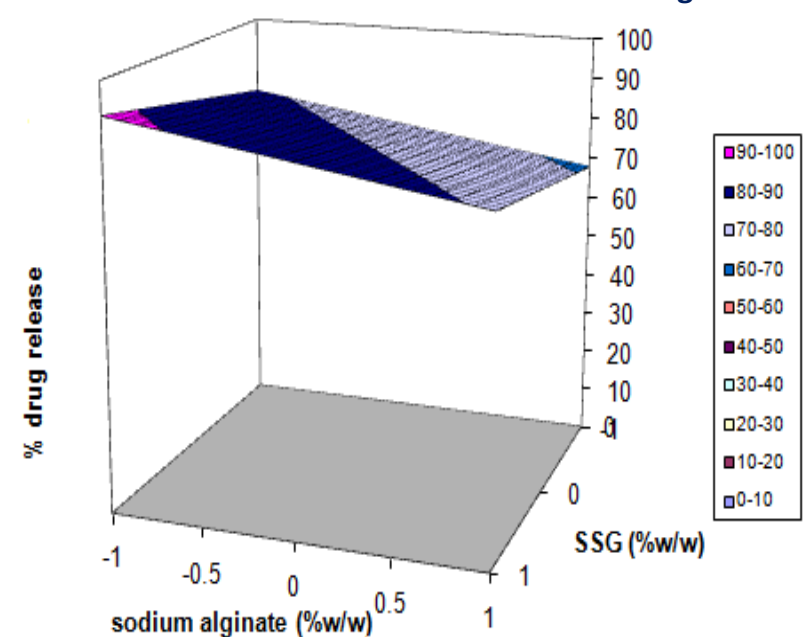

Figure 2: Res ponse surface curve for amlodipine besylate films after 6 minutes dissolution

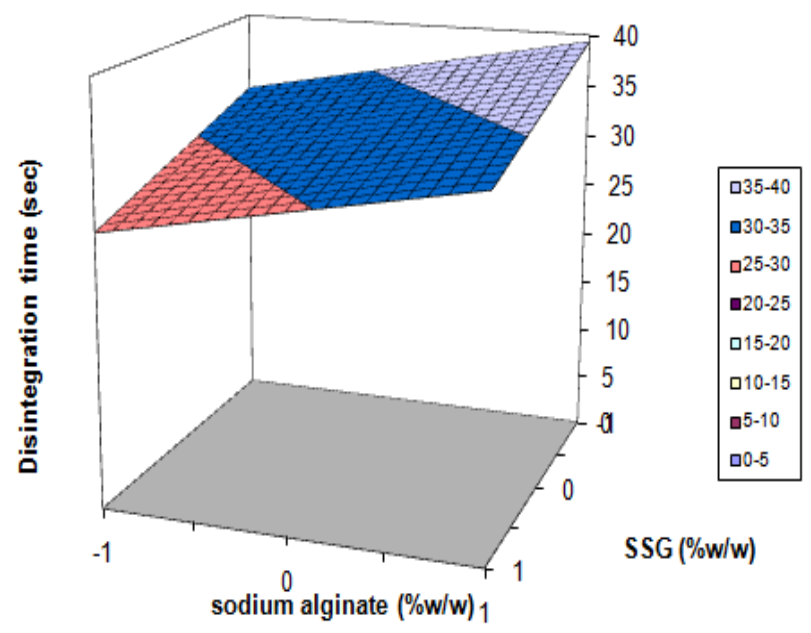

Figure 3: Res ponse surface curve for films showing the time at which disintegration initialized

Table 4: Actual vs. Predicted res ponse of various de pendent variables

\begin{tabular}{|c|c|c|c|c|c|}
\hline \multirow{2}{*}{ S.No. } & \multirow{2}{*}{ Code } & \multicolumn{2}{|c|}{ \% cumulative dr ug release after 6 minutes } & \multicolumn{2}{c|}{ Disintegration time (Sec) } \\
\cline { 3 - 6 } & & Actual & Predicted & Actual & Predicted \\
\hline 1 & F1 & 81.45 & 80.12968 & 32 & 32.29165 \\
\hline 2 & F2 & 84.43 & 82.86383 & 28 & 30.7083 \\
\hline 3 & F3 & 90.4 & 85.59798 & 25 & 29.12495 \\
\hline 4 & F4 & 79.2 & 78.488 & 35 & 33.16665 \\
\hline 5 & F5 & 82.19 & 81.22215 & 38 & 31.5833 \\
\hline 6 & F6 & 86.67 & 83.9563 & 30 & 29.99995 \\
\hline 7 & F7 & 65.09 & 76.84633 & 39 & 34.04165 \\
\hline 8 & F8 & 70.31 & 79.58048 & 35 & 32.4583 \\
\hline 9 & F9 & 81.48 & 82.31463 & 32 & 30.87495 \\
\hline
\end{tabular}

\section{CONCLUSION:}

It was concluded that the fast dissolving strips of amlodipine besylate can be made by solvent casting technique with enhanced dissolution rate, taste masking, and hence better patient compliance and effective therapy.

\section{REFERENCES :-}

1. Ary a A, Chandra A, Sharma V, Pathak K. Fast dissolving strips: A novel approach for the delivery of verapamil, Int.J. ChemTech Res, 2010, 2(1).

2. Kerins DM, Robertson RM, Robertson D. Chapter 32. Drugs and the drugs used for the treatment of myocardial ischemia. Goodman \& Gilman's the Pharmacological Basis of Therapeutics. 10th Ed. JG Hardman, LE Limbird, AG. Gilman, eds. McGraw-Hill, New York, 2001; 84363.

3. Available at http://www.rxlist.com/norvasc- drug.html.

4. Available at http://www.drugs.com/pdr/amlodipinebesylate.html.

5. Rowe RC, Sheskey PJ, Owen SC, Sodium starch glycolate, Pharmaceutical Excipients, Pharmaceutical Press and the American Pharmacists Association.

6. Rowe RC, Sheskey PJ, Owen SC, Glycerine, Pharmaceutical Excipients, Pharmaceutical Press and the American Pharcists Association.

7. Shimoda H, Taniguchi K, Nishimura M, Matsuura K, Tsukioka T, Yamashita $\mathrm{H}$ et al. . Preparation of a fast dissolving oral thin film containing dexamethasone,
European Journal of Pharmaceutics and Biopharmaceutics, 2009, 73, 361-365.

8. Patel R, Shardul N, Patel J, Baria A. Formulation, development \& evaluation of oral fast dissolving antiallergic film of levocetrizine dihy drochloride Arch Pharm Sci \& Res, 2009, 1(2), $212-217$.

9. Mahesh A, Shastri N, Sadanandam M. Development of taste masked fast disintegrating films of levocetirizine dihydrochloride for oral use. Curr Drug Deliv. 2010; 7:21-7.

10. Patel R, Naik S, Patel J, Baria A. Formulation development and evaluation of mouth melting film of ondansetron. Arch Pharm Sci Res. 2009; 1:212-7.

11. Mohammed A, Harish N, Charyulu R, Prabhu P. Formulation of chitosan-based ciprofloxacin and diclofenac film for periodontitis therapy. Trop J Pharm Res. 2009; 8:33-41.

12. Siewert M, Dressman J, Brown CK, Shah VP. FIP; AAPS. FIP/AAPS guidelines for dissolution/in vitro release testing of novel/special dosage forms. AAPS PharmSciTech. 2003; 4:E7. 